\title{
Intraoperative Lumbar Drain Placement in Endoscopic Neurosurgical Procedures: Technical Challenges and Complications-A Prospective Observational Study
}

\author{
Mridul S. Koshy ${ }^{1}$ Georgene Singh ${ }^{2}$ Bijesh Yadav ${ }^{3}$ \\ Liby G. Pappachan² \\ ${ }^{1}$ Department of Anaesthesia and Critical Care, Amrita Hospital, \\ Kochi, Kerala, India \\ ${ }^{2}$ Department of Anaesthesiology, Christian Medical College, \\ Vellore, Tamil Nadu, India \\ ${ }^{3}$ Department of Biostatistics, Christian Medical College, Vellore, \\ Tamil Nadu, India \\ ${ }^{4}$ Department of Neurosurgery, Christian Medical College, Vellore, \\ Tamil Nadu, India
}

\section{Ramamani Mariappan² Krishnaprabhu ${ }^{4}$}

\author{
Address for correspondence Liby G. Pappachan, MD, \\ Department of Anaesthesiology, Christian Medical College, \\ Vellore, Ida Scudder Road, Tamil Nadu 632004, India \\ (e-mail: libyjohnmathew@gmail.com).
}

\begin{abstract}
Keywords

- lumbar drain

- epidural catheter

- endoscopic surgery

- transnasal transsphenoidal surgery

- technical difficulties

- complications

Background Perioperative placement of lumbar drain (LD) is being increasingly preferred in the endoscopic base of skull procedures to provide optimal surgical conditions. This study aims to determine the incidence of technical difficulties and complications associated with LD placement.

Materials and Methods A total of 50 patients undergoing transnasal transsphenoidal surgery were included in the study after obtaining written informed consent. Intraoperatively, LD was placed using an 18-gauge epidural catheter. Technical difficulties in LD placement were assessed by the number of attempts, levels attempted, difficulty in siting catheter, and obtaining free flow of cerebrospinal fluid (CSF). The incidence of complications such as postdural puncture headache (PDPH), meningitis headache, and backache was studied.

Results Successful LD placement in the first attempt was obtained in $36 \%$ of the patients. Technical difficulties were encountered in $64 \%$ of the patients. Despite successful LD placement in $90 \%$ of the patients, $32 \%$ required manipulations to increase CSF flow. The drain failure rate was $10 \%$. Drainage of $>20$ to $30 \mathrm{~mL}$ of CSF/hour was significantly associated with better surgical conditions $(p<0.05)$. The incidence of headache was $56 \%$ and that of backache was $26 \%$. Headache was significantly related to difficulty in tapping CSF ( $p=0.032)$, and backache was significantly related to the number of attempts $(p<0.001)$, levels attempted $(p=0.001)$, and large CSF volume $(p=0.004)$. There were no incidences of PDPH or meningitis in our series.

Conclusion We conclude that the incidence of technical difficulties in LD placement with epidural catheters is high. Use of standard well-functioning LD catheters will assist in improving surgical conditions.
\end{abstract}

Published online June 30, 2020
DOI https://doi.org/ $10.1055 / \mathrm{s}-0040-1713560$ ISSN 2348-0548. (c) 2020. Indian Society of Neuroanaesthesiology and Critical Care. This is an open access article published by Thieme under the terms of the Creative Commons Attribution-NonDerivative-NonCommercial-License, permitting copying and reproduction so long as the original work is given appropriate credit. Contents may not be used for commercial purposes, or adapted, remixed, transformed or built upon. (https://creativecommons.org/licenses/by-nc-nd/4.0/).

Thieme Medical and Scientific Publishers Pvt. Ltd. A-12, 2nd Floor, Sector 2, Noida-201301 UP, India 


\section{Introduction}

In endoscopic procedures of the skull base, lumbar drain (LD) placement is required perioperatively to improve surgical conditions and is an important procedural skill in the armamentarium of the anesthesiologist. ${ }^{1}$

The goal of $L D$ placement is to ensure a free, unobstructed flow of cerebrospinal fluid (CSF) to facilitate tumor removal, and to reduce intraoperative CSF leak. It also aids in bringing the superior portion of suprasellar tumors into the sella by the injection of air or saline and offers a therapeutic benefit in those with postoperative CSF leaks. ${ }^{2}$ Insertion of LD is an invasive procedure associated with technical challenges and complications (5\% minor and 3\% major complication rate)., ${ }^{3,-7}$ Often, $L D$ is placed with epidural catheters instead of the standard LD catheters due to its prohibitive cost and unavailability.

Our study aimed to assess the incidence of technical challenges and complications with LD placement for endoscopic procedures. To our knowledge, there is a paucity of data on this aspect. We hypothesized that the incidence of technical challenges associated with LD placement using an epidural catheter is higher than with standard LD.

\section{Materials and Methods}

After approval from the Institutional Review Board (IRB Min No:10525 [OBSERVE] dated February 1, 2017), this prospective observational study was conducted in a tertiary care hospital over a period of 10 months.

A total of 50 American Society of Anesthesiologists (ASA) class I to III patients between 18 and 70 years of age scheduled for elective endoscopic neurosurgical procedures requiring LD were included in the study after obtaining written informed consent. The decision to insert LD was made by the operating surgeon depending on the nature of the surgery. The exclusion criteria included patient refusal, history of bleeding diathesis or deranged coagulation, local infection, systemic sepsis, meningitis (treated within the past 6 months), previous spinal surgery, preexisting neurologic deficits, clinical features of raised intracranial pressure, demyelinating lesions, CSF leak, or emergency procedures.

The 18-gauge epidural catheter (Portex [Smiths Medical] or BD Perisafe) was used as per the anesthesiologist's preference. The anesthesiologist involved in the placement of LD had more than five years of clinical experience. The technique of LD placement (midline vs. paramedian approach), timing of placement (awake vs. anesthetized), and level of placement were decided by the concerned anesthesiologist at the time of surgery. All LD placements were performed under standard sterile precautions, and the catheters were fixed to the skin with transparent film dressing (3M Tegaderm). The LD was allowed to drain at a rate of 20 to $30 \mathrm{~mL} /$ hour. The flow rate was adjusted to meet the surgical requirements, and LD was removed at the end of surgery if there was no CSF leak. If there was a CSF leak, the LD was left in place for a maximum of 5 days with antibiotic prophylaxis.
All patients received perioperative surgical prophylaxis as per institutional guidelines with ceftriaxone $2 \mathrm{~g}$ intravenously 30 minutes before incision and were treated with intravenous paracetamol $20 \mathrm{mg} / \mathrm{kg}$ every 8 hours and ondansetron $0.15 \mathrm{mg} / \mathrm{kg}$ every 8 hours for the first 24 hours and oral paracetamol for the next 24 hours. Based on the pilot study performed in our department, the prevalence of technical difficulty in LD patients was around $25 \%$ and the sample size calculated was 72 . The expected sample size could not be achieved due to time constraints. A total of 50 cases were studied.

All demographic details, ASA class, and indication for the placement of LD were obtained. Technical difficulties with LD placement such as difficulty in tapping CSF space, number of attempts, number of levels attempted, difficulty in siting catheter, CSF drainage after final positioning, manipulations required to improve CSF flow, the total volume of CSF drained, and the intraoperative conditions as assessed by the surgeon were documented by the anesthesiologist. After removal of the catheter, the catheter tip was inspected to rule out any fracture of the catheter tip. The patients were kept in the supine position for at least 6 hours after removal of the LD and were ambulated thereafter.

The primary investigator followed up the patients during the next 48 hours and documented the outcome parameters related to complications associated with the LD as per the defined criteria ( - Appendix A). Patients with LD in the postoperative period were followed up for 48 hours after removal of LD. Complications such as headache, postdural puncture headache (PDPH), backache, and others were studied over the period. The duration of hospitalization was also studied.

\section{Statistical Analysis}

Continuous data were expressed as mean (standard deviation) or as median (interquartile), whereas categorical data were expressed as numbers and percentages. The incidence of the complication rate was given with $95 \%$ confidence interval. The relation between complication rate and continuous variables was analyzed using independent $t$-test. A value of $p<0.05$ was considered significant.

\section{Results}

The demographic details are presented in -Table 1 . A total of 50 patients were included in the study (56\% males; $44 \%$ females). Of the patients, $92 \%$ underwent pituitary surgery, with $78 \%$ of them presenting with macroadenoma and $74 \%$ having suprasellar extension.

The technical difficulties and complications associated with LD placement are presented in - Table 2. Of the LD, 90\% were inserted in the anesthetized patient with midline being the preferred approach (88\%).

Technical difficulties were present in $64 \%$, with a technical failure rate of $2 \%$. In more than $90 \%$ of them, there was difficulty in obtaining CSF tap, with 52\% requiring more than two attempts and $45 \%$ required an attempt at a different level. Difficulty in siting the catheter was observed in $47 \%$. 
Table 1 Demographic details

\begin{tabular}{|l|l|l|}
\hline & Mean & Range (SD) \\
\hline Age (years) & 42.18 & $18-76(14.26)$ \\
\hline Weight (kilograms) & 83.14 & $43-110(95.86)$ \\
\hline BMI & 26.48 & $16.9-33.9(4.37)$ \\
\hline \multirow{3}{*}{ Gender } & Description & Number (\%) \\
\hline \multirow{3}{*}{ ASA } & Male & $28(56)$ \\
\cline { 2 - 3 } & Female & $22(44)$ \\
\hline \multirow{3}{*}{ Tumor type } & 1 & 0 \\
\cline { 2 - 3 } & 2 & $50(100)$ \\
\hline \multirow{3}{*}{ Suprasellar extension } & Macroadenoma & $39(78)$ \\
\cline { 2 - 3 } & Microadenoma & $7(14)$ \\
\cline { 2 - 3 } & Unclassified & $4(8)$ \\
\cline { 2 - 3 } & No & $37(74)$ \\
\hline History of EVD/LSAD & Yes & $13(26)$ \\
\cline { 2 - 3 } & No & $5(10)$ \\
\hline History of meningitis & Yes & $49(90)$ \\
\cline { 2 - 3 } & No & $498)$ \\
\hline
\end{tabular}

Abbreviations: ASA, American Society of Anesthesiologists; BMI, body mass index; EVD, external ventricular drainage; LSAD, lumbar subarachnoid drainage; SD, standard deviation.

Table 2 Details of lumbar drain placement and technical difficulties encountered in the placement of lumbar drains

\begin{tabular}{|c|c|}
\hline Variables & $n(\%)$ \\
\hline \multicolumn{2}{|l|}{ Timing of placement } \\
\hline Awake & $5(10)$ \\
\hline Anesthetized & $45(90)$ \\
\hline \multicolumn{2}{|l|}{ Approach } \\
\hline Midline & $6(12)$ \\
\hline Paramedian & $44(88)$ \\
\hline Difficulties encountered in the placement of LSAD & $32(64)$ \\
\hline Difficulty in tapping & 29/32 (91) \\
\hline \multicolumn{2}{|l|}{ Number of attempts } \\
\hline$<2$ & $14 / 29(48)$ \\
\hline$>2$ & $15 / 29(52)$ \\
\hline \multicolumn{2}{|l|}{ Number of levels attempted } \\
\hline 1 & $16 / 29(55)$ \\
\hline$\geq 2$ & $13 / 29(45)$ \\
\hline Difficulty in siting the catheter & $15 / 32(47)$ \\
\hline Unable to site the catheter & $1 / 32(3)$ \\
\hline $\begin{array}{l}\text { Decrease in the CSF flow after final positioning } \\
\text { requiring manipulation }\end{array}$ & $16 / 50(32)$ \\
\hline Significantly reduced CSF flow after manipulation & $4 / 50(8)$ \\
\hline Unable to drain CSF & $1 / 50(2)$ \\
\hline Drain failure rate & $5 / 50(10)$ \\
\hline
\end{tabular}

Abbreviations: CSF, cerebrospinal fluid; LSAD, lumbar subarachnoid drainage.
After successful LD placement, repositioning the patient to the supine position reduced the flow of the CSF ( $<10 \mathrm{~mL} /$ hour) in $32 \%$. Manipulations such as flexion of the legs, placement of sandbags under the hips, retraction of the catheter, and flushing of the catheter improved the flow in 10 patients, and the flow was $<10 \mathrm{~mL} /$ hour in four patients, with one patient having no CSF flow. Technical difficulty was not related to age, sex, body mass index (BMI), experience of the anesthesiologist, nature of tumor, or suprasellar extension. There were no major patient-related complications fulfilling the criteria for PDPH, meningitis, nerve root irritation, or retained catheter, or intracranial complications causing neurologic decline. There was a $56 \%$ incidence of headache and $26 \%$ incidence of backache (-Table 3 ). The demographic factors (sex, age, BMI, weight) that may contribute to difficult LD placement were nonsignificant $(\mathrm{p}>0.05)$.

- Table 4 shows that there is a statistically significant correlation between the drainage of higher CSF volumes (>30 mL/hour) and better intraoperative conditions as assessed subjectively by the surgeon based on the absence of arachnoid folds in the surgical field.

The presence of headache was significantly related to the difficulty in tapping the $\operatorname{CSF}(p=0.032)$ ( - Table 5). Backache

Table 3 Analysis of patient-related and technical complications

\begin{tabular}{|l|l|l|}
\hline Variables & $N(\%)$ & $\begin{array}{l}\text { 95\% confidence } \\
\text { interval }\end{array}$ \\
\hline Technical complications \\
\hline Insufficient CSF drainage & $5(10)$ & $3.3-21.8$ \\
\hline Dressing changes for LSAD & $7(14)$ & $5.8-26.7$ \\
\hline LSAD system change & $7(14)$ & $5.8-26.7$ \\
\hline Patient complications & $23(56)$ & $41.2-70$ \\
\hline Headache & 0 & $0-7.1$ \\
\hline Postdural puncture headache & $13(26)$ & $14.6-40.3$ \\
\hline Backache & 0 & $0-7.1$ \\
\hline Meningitis & 0 & $0-7.1$ \\
\hline Nerve root irritation & 0 & $0-7.1$ \\
\hline Retained catheter & 0 & $0-7.1$ \\
\hline $\begin{array}{l}\text { Skin changes such as } \\
\text { erythema/induration }\end{array}$ & 0 & $0-7.1$ \\
\hline Intracranial complications &
\end{tabular}

Abbreviations: CSF, cerebrospinal fluid; LSAD, lumbar subarachnoid drainage.

Table 4 Mean CSF volume drained and intraoperative conditions

\begin{tabular}{|l|l|l|l|}
\hline \multirow{2}{*}{$\begin{array}{l}\text { Intraoperative } \\
\text { conditions }\end{array}$} & \multicolumn{2}{|c|}{ Mean volume of CSF } & \multirow{2}{*}{-Value } \\
\cline { 2 - 3 } & Mean & SD & \\
\hline Unsatisfactory & 18.25 & 16.71 & \\
\hline Satisfactory & 85.31 & 46.85 & \multirow{2}{*}{0.0003} \\
\hline Excellent & 91.92 & 46.93 & \\
\hline
\end{tabular}

Abbreviations: CSF, cerebrospinal fluid; SD, standard deviation. 
Table 5 Technical difficulties and their relationship with patient-related complications

\begin{tabular}{|c|c|c|c|c|c|c|c|}
\hline & & Headache & No headache & $p$-Value & Backache & No backache & $p$-Value \\
\hline \multirow{2}{*}{$\begin{array}{l}\text { Difficulty in } \\
\text { tapping CSF }\end{array}$} & Yes & 19 (90.5\%) & $6(54.55 \%)$ & \multirow[t]{2}{*}{0.032} & $5(41.7 \%)$ & $5(25 \%)$ & \multirow[t]{2}{*}{0.325} \\
\hline & No & $2(9.52 \%)$ & $5(45.45 \%)$ & & $7(58.3 \%)$ & 15 (75\%) & \\
\hline \multirow{3}{*}{$\begin{array}{l}\text { Number of } \\
\text { attempts }\end{array}$} & 1 & $2(9.52 \%)$ & $1(12.5 \%)$ & \multirow[t]{3}{*}{0.924} & $2(15.38 \%)$ & 22 (59.46\%) & \multirow[t]{3}{*}{$<0.001$} \\
\hline & 2 & $8(38.1 \%)$ & $3(37.5 \%)$ & & $1(7.7 \%)$ & $10(27.03 \%)$ & \\
\hline & 3 & $11(52.4 \%)$ & $4(50 \%)$ & & $10(70.7 \%)$ & $5(13.51 \%)$ & \\
\hline \multirow{3}{*}{$\begin{array}{l}\text { Number } \\
\text { of levels } \\
\text { attempted }\end{array}$} & 1 & $10(47.62 \%)$ & $6(75 \%)$ & \multirow[t]{3}{*}{0.44} & $5(38.46 \%)$ & $32(86.5 \%)$ & \multirow[t]{3}{*}{0.001} \\
\hline & 2 & $9(42.86 \%)$ & $2(25 \%)$ & & $6(46.15 \%)$ & $5(13.5 \%)$ & \\
\hline & 3 & $2(9.52 \%)$ & 0 & & $2(15.38 \%)$ & 0 & \\
\hline $\begin{array}{l}\text { Mean CSF } \\
\text { Volume }(\mathrm{mL})\end{array}$ & & $83.71 \pm 57.02$ & $66.86 \pm 38.45$ & 0.479 & $57.38 \pm 58.35$ & $82.95 \pm 45.7$ & 0.004 \\
\hline
\end{tabular}

Abbreviations: CSF, cerebrospinal fluid; LSAD, lumbar subarachnoid drainage.

was significantly related to the number of attempts $(p<0.001)$ and the number of levels attempted $(p<0.001)$ ( - Table 5 ). There was a significant decrease in backache in those with higher CSF volumes $(\mathrm{p}=0.04)$. Both headache and backache were not significantly related to age, sex, BMI, experience of the anesthesiologist, nature of tumor, or suprasellar extension. Duration of hospitalization was significantly prolonged in those with CSF leak $(p=0.03)$.

\section{Discussion}

In our study, difficult LD placement was observed in 64\% with a technical failure rate of $2 \%$.

In a similar study by Qureshi et $a{ }^{8}{ }^{8}$ fluoroscopy-guided LD placement was attempted to decrease the incidence of technical difficulties. They used large catheters (14-gauge), prone position, awake patients, and paramedian approach for all procedures, and had a comparable technical failure rate of $2.32 \%$. Most anesthesiologists preferred to perform the procedure in intubated patients through the midline approach, which is similar to the study by Mehta and Oldfield ${ }^{1}$ and Ransom and Chiu. ${ }^{9}$

There was a decrease in CSF flow, with final positioning to supine in approximately 33\%. There are no studies that have reported on this aspect, although it is a pertinent practical problem intraoperatively since neither manipulations nor repositioning is feasible after final positioning. Since there is a paucity of data, we assume that this may not be a problem with the larger gauge wire reinforced catheters, which are commonly used in high-volume centers, and is probably unique to the smaller gauge nylon catheters which are intended for epidural infusions.

The standard LD system consists of a specifically designed wire reinforced Codman's catheter. ${ }^{10}$ Owing to its high cost and unavailability, the 16-gauge epidural Tuohy needle with an 18-gauge catheter is commonly used. Our study demonstrates significant difficulty associated with CSF drainage with the use of nylon catheters, resulting in suboptimal surgical conditions.

Wynn et al has shown that the drain failure rate was 7.8\% for small drains (19-gauge) and 1.7\% for large silicone drains (16-gauge). ${ }^{11}$ In our study, the drain failure rate was $10 \%$, which could be due to the use of small nylon catheters. Silicone catheters have been demonstrated to be superior to nylon catheters. ${ }^{12}$ The mean volume of CSF drained was $76.3 \mathrm{~mL}$ over 3 to 4 hours. Wynn et a ${ }^{11}$ has shown that the mean volume of CSF drained by a small catheter and a large catheter to be comparable.

The complications that usually occur are PDPH, injury to the Lumbosacral nerves, infections, retained catheter fragments and over drainage, ${ }^{1,6}$ herniation, intradural hematoma, subdural hematoma, pneumocephalus, and neurologic decline. ${ }^{12-14}$ The incidence of headache in our study is comparable to the findings of Kitchel et $\mathrm{al}^{15}$ (58\%) and Shapiro and Scully ${ }^{12}(63 \%)$.

None of our patients presented with PDPH. Wynn et $\mathrm{al}^{11}$ has shown that the incidence of PDPH was $0.6 \%$ in small drains and $2.3 \%$ in large drains. In the study by Youngblood et al, ${ }^{16}$ the incidence of PDPH was 9.7\%. The mean CSF drained was $128 \mathrm{~mL}$, whereas in our study, it was only $76.3 \mathrm{~mL}$. In concordance with this, we found that in the subgroup of patients with headache, there was an insignificant but definite increase in the volume of CSF that was drained. However, we have not considered obstructive hydrocephalus as a cause of a decrease in CSF drainage.

The incidence of backache was 26\%. Although this is only a minor complication and is not reported by any other study, it is an important consideration in the quality of care. The presence of CSF leak significantly increased the duration of hospitalization by 4.69 days. This is comparable with the findings of Jung et $\mathrm{al}^{3}$ and hence the need for a well-functioning LD.

We would like to conclude by affirming with Wynn et $\mathrm{al}^{11}$ that the rate of difficulty in LD placement is unacceptably high with the use of epidural catheters as LD. Moreover, a drain failure rate of $10 \%$ after successful LD placement mandates that large-drain catheters, specifically designed for CSF drainage, must be used. Since the rate of technical failure is only $2 \%$ in our study, the use of fluoroscopy as the first line of treatment for the placement of $L D$ is questionable but should definitely be considered as the second line of treatment. 


\section{Limitation}

Our study was performed for a period of 10 months with a limited sample size (50 patients). Our follow-up lasted for only 48 hours after LD removal. Hence, complications thereafter were not assessed.

\section{Conclusion}

The incidence of technical difficulties in LD placement with the use of epidural catheters is high. However, the incidence of major complications is minimal when the procedure is performed using standard protocols by experienced anesthesiologists. With increases in endoscopic approach for skull base procedures, the need for LD with free flow of CSF is of utmost importance for successful surgical outcomes, thus mandating the availability of standard LD catheters and the need for perfection in the placement of a well-functioning LD.

Conflict of Interest

None declared.

\section{References}

1 Mehta GU, Oldfield EH. Prevention of intraoperative cerebrospinal fluid leaks by lumbar cerebrospinal fluid drainage during surgery for pituitary macroadenomas. J Neurosurg 2012;116(6):1299-1303

2 Caggiano C, Penn DL, Laws ER Jr. The role of the lumbar drain in endoscopic endonasal skull base surgery: a retrospective analysis of 811 cases. World Neurosurg 2018;117:e575-e579

3 Jung $H$, Shah A, Ajlan A. Perioperative cerebrospinal fluid diversion utilizing lumbar drains in transsphenoidal surgery. Neurosciences (Riyadh) 2018;23(1):46-51

4 Governale LS, Fein N, Logsdon J, Black PM. Techniques and complications of external lumbar drainage for normal pressure hydrocephalus. Neurosurgery 2008;63(4, Suppl 2):379-384
5 Açikbaş SC, Akyüz M, Kazan S, Tuncer R. Complications of closed continuous lumbar drainage of cerebrospinal fluid. Acta Neurochir (Wien) 2002;144(5):475-480

6 Stokken J, Recinos PF, Woodard T, Sindwani R. The utility of lumbar drains in modern endoscopic skull base surgery. Curr Opin Otolaryngol Head Neck Surg 2015;23(1):78-82

7 Hagel S, Bruns T, Pletz MW, Engel C, Kalff R, Ewald C. External ventricular drain infections: risk factors and outcome. Interdiscip Perspect Infect Dis 2014;2014:708531

8 Qureshi AI, Khan AA, Malik AA, et al. Lumbar catheter placement using paramedian approach under fluoroscopic guidance. J Vasc Interv Neurol 2016;8(5):55-62

9 Ransom ER, Chiu AG. Prevention and management of complications in intracranial endoscopic skull base surgery. Otolaryngol Clin North Am 2010;43(4):875-895

10 DePuy Synthes. Lumbar External Drainage System. Available at: https://www.depuysynthes.com/hcp/codman-neuro/products/qs/LumbarExternal-Drainage-System. Accessed May 26. 2020

11 Wynn MM, Mell MW, Tefera G, Hoch JR, Acher CW. Complications of spinal fluid drainage in thoracoabdominal aortic aneurysm repair: a report of 486 patients treated from 1987 to 2008. J Vasc Surg 2009;49(1):29-34

12 Shapiro SA, Scully T. Closed continuous drainage of cerebrospinal fluid via a lumbar subarachnoid catheter for treatment or prevention of cranial/spinal cerebrospinal fluid fistula. Neurosurgery 1992;30(2):241-245

13 VIVO. Prolonged lumbar spinal drainage after the resection of tumors of the skull base: a cautionary note. Available at: http://vivo.med.cornell.edu/display/pubid0025803759. Accessed May 26. 2020

14 Graf CJ, Gross CE, Beck DW. Complications of spinal drainage in the management of cerebrospinal fluid fistula. J Neurosurg 1981;54(3):392-395

15 Kitchel SH, Eismont FJ, Green BA. Closed subarachnoid drainage for management of cerebrospinal fluid leak after an operation on the spine. J Bone Joint Surg Am 1989;71:984-987

16 Youngblood SC, Tolpin DA, LeMaire SA. Coselli JS, Lee VV, Cooper JR Jr. Complications of cerebrospinal fluid drainage after thoracic aortic surgery: a review of 504 patients over 5 years. J Thorac Cardiovasc Surg 2013;146(1):166-171

\section{Appendix A}

1. Headache was defined as pain in the head having no relationship with postural variation and not accompanied by vomiting and is $>3$ on the numerical rating scale (NRS).

2. Meningitis was defined as fever (temperature $\geq 100^{\circ} \mathrm{F}$ ) with neck stiffness and a positive cerebrospinal fluid culture.

3. Nerve root irritation was defined as numbness, tingling, radicular pain, or sensorimotor deficit in the lower extremity.

4. Retained catheter tip was defined as a break in the epidural catheter tip noticed on removal of the epidural catheter.

5. Postdural puncture headache was defined as pain in the head involving the back and front of the head and spreading to the neck and shoulders, with or without neck stiffness, nausea/vomiting, which is exacerbated by movement, and sitting or standing, relieved to some degree by lying down, and is $\geq 5$ on the NRS.

6. Backache was defined as pain, with or without stiffness, in the lumbosacral region and is $\geq 5$ on the NRS. 